\section{Psicologia Escolar \\ e Educacional}

ARTIGO

DOI: http://dx.doi.org/10.1590/2175-35392020200988

Elocid - e200988

\title{
PROCESSOS DE CRIMINALIZAÇÃO DA POBREZA NO TERRITÓRIO ESCOLAR
}

\author{
Patrick Silva Botelho ${ }^{1} \mathbb{D}$; Thiago Colmenero Cunha ${ }^{1} \mathbb{D}$; Pedro Paulo Gastalho de Bicalho ${ }^{1} \mathbb{D}$ \\ RESUMO
}

O artigo é efeito de análises de pesquisa-intervenção realizada em um estabelecimento educacional, localizado em região periférica da cidade do Rio de Janeiro e apresenta reflexões acerca do cotidiano das escolas públicas brasileiras, analisando as possíveis interseções entre as demandas apresentadas e o processo de criminalização da pobreza existente em curso na sociedade. Julga-se importante compreender de que forma a Psicologia pode atuar frente às demandas escolares a fim de não contribuir com o contexto de exclusão e criminalização vivenciado por discentes oriundos das camadas populares. Aposta-se em uma forma de intervenção que se afaste das lógicas de individualização, culpabilização e judicialização da vida escolar. Como resultado, o estudo proporcionou a criação de espaços de reflexão aos estudantes, possibilitando análise do cotidiano escolar e da sua vivência em sociedade, visando a construção de um processo de autonomia e inventividade dos jovens.

Palavras-chave: Psicologia Escolar; problemas sociais; adolescentes.

\section{Procedures for criminalizing poverty in school territory}

\begin{abstract}
The article is the effect of analysis of intervention research conducted in an educational establishment located in a peripheral region of the city of Rio de Janeiro and presents reflections on the daily life of Brazilian public schools, analyzing the possible intersections between the demands presented and the criminalization process existing poverty in society. It is important to understand how Psychology can act against school demands in order not to contribute to the context of exclusion and criminalization experienced by students from the lower classes. The intervention is a bet that deviates from the logic of individualization, blaming and judicialize way of school life. As a result, the study provided the creation of reflection spaces for students, allowing analysis of school daily life and their experience in society, aiming at the construction of a process of autonomy and inventiveness of young people.
\end{abstract}

Keywords: School psychology; social problems; adolescents.

\section{Procesos de criminalización de la pobreza en el territorio escolar}

\section{RESUMEN}

El artículo es efecto de análisis de investigación-intervención realizada en un establecimiento educacional, localizado en región periférica de la ciudad de Rio de Janeiro y presenta reflexiones acerca del cotidiano de las escuelas públicas brasileñas, analizando las posibles intersecciones entre las demandas presentadas y el proceso de criminalización de la pobreza existente en curso en la sociedad. Se juzga importante comprender de qué forma la Psicología puede actuar frente a las demandas escolares a fin de no contribuir con el contexto de exclusión y criminalización vivenciados por discentes derivadas de las camadas populares. Se apuesta en una forma de intervención que se aleje de las lógicas de individualización, culpabilidad y judicialización de la vida escolar. Como resultado, el estudio proporcionó la creación de espacios de reflexión a los estudiantes, posibilitando análisis del cotidiano escolar y de su vivencia en sociedad, visando la construcción de un proceso de autonomía e invectividad de los jóvenes.

Palabras clave: Psicología escolar; problemas sociales; adolescentes.

${ }^{1}$ Universidade Federal do Rio de Janeiro - Rio de Janeiro-RJ - Brasil; patrickbotelho9@gmail.com; colmenerocunha@gmail.com; ppbicalho@ufrj.br 


\section{INTRODUÇÃO}

O presente artigo descreve a produção de conhecimento que emerge da pesquisa-intervenção "Psicologia e criminalização da pobreza nas escolas: história, reflexões e análise do cotidiano escolar" ${ }^{11}$, cujo objetivo foi analisar os discursos produzidos na escola que auxiliam à criminalização dos alunos pertencentes às classes populares da sociedade.

A pesquisa foi realizada em uma escola municipal, localizada em uma região considerada periférica da cidade do Rio de Janeiro. Nesse espaço, durante o ano de 2017, ocorreu a realização de encontros em grupo e entrevistas individuais com alunos que foram identificados pelo estabelecimento educacional como 'portadores' de algum "problema" relacionado ao comportamento, ao baixo rendimento escolar e outras questões inerentes à vida escolar.

Buscou-se através das atividades realizadas mapear as relações presentes entre os atores pertencentes ao espaço - alunos, professores, direção e coordenação pedagógica. Numa instituição marcada por práticas cristalizadas, procurou-se propiciar um campo de reflexão aos jovens, no qual pudessem refletir sobre a sua vivência na escola e em sociedade, diferenciando-os do modo de ser "aluno-problema".

Desse modo, verificou-se a presença de práticas e discursos que auxiliam a exclusão e estigmatização dos discentes. Nesses encontros foram enunciadas falas que justificavam o comportamento "inadequado" dos estudantes a partir do seu modo de viver em sociedade; por vezes localizavam na família e no bairro a causa pelas questões apresentadas no espaço.

Apesar de a pesquisa ter sido realizada em uma escola pública do Rio de Janeiro, um município que possui particularidades em sua dinâmica de funcionamento, os acontecimentos vivenciados nesse espaço não se limitam a fatos isolados, os quais ocorreriam somente nas unidades escolares desta cidade. Acredita-se que as situações apresentadas, ao longo desse artigo, possuem relações com o modo de funcionamento da sociedade e podem ser presenciadas de forma semelhante em outras unidades escolares espalhadas pelo país. Nesse sentido, este texto não pretende culpabilizar os atores que compõem as escolas públicas.

Entende-se que os problemas enfrentados fazem parte de uma rede muito maior, que extrapola os muros dos estabelecimentos educacionais. Esses fatos são frutos de um projeto político, econômico e social, que têm como objetivo a manutenção do contexto de precarização da educação pública e a retirada de direitos da população menos abastada do país (Bicalho, 2013).

\footnotetext{
${ }^{1}$ A pesquisa está registrada no Comitê de Ética do Centro de Filosofia e Ciências Humanas da Universidade Federal do Rio de Janeiro, sob o número CAAE: 69372617.0.0000.5582.
}

Por sua vez, torna-se necessário analisar a atuação da psicologia na manutenção do quadro de criminalização e exclusão vivenciado por estudantes oriundos das camadas populares nas escolas (Melsert \& Bicalho, 2012). Reconhecer que essa área do saber tem um histórico de contribuição na construção e legitimação de discursos individualizantes, patologizantes, criminalizantes e recheados de psicologismos (em forma de intimismos) ao compreender as demandas escolares é uma forma potente de colocar em análise a práxis no espaço (Cassal, Gonzalez, \& Bicalho, 2011).

Exige-se dos profissionais de educação a criação de novas formas de habitar o território, os quais devem oferecer à sociedade mecanismos capazes de fazer repensar o seu funcionamento (Bortolini et al.,2014). Portanto, julga-se importante contribuições da psicologia a fim de que esta área torne-se aliada dos educadores pela construção de um espaço que seja para todos. Para isso será necessário trabalhar em coletivo, desmontando o saber de especialista que historicamente compõe o campo.

Assim, torna-se necessário compreender as relações que constituem o funcionamento dos estabelecimentos educacionais e o contexto de criminalização da pobreza em sociedade (Decotelli, Cunha, \& Bicalho, 2016), com a finalidade de evitar a produção de discursos que visam a culpabilização dos indivíduos que estão no "chão das escolas", como professores, diretores, coordenadores pedagógicos. Esses estão diariamente lutando, dentro das suas possibilidades, para a construção de uma educação pública de qualidade, ainda que convivam com inúmeras dificuldades para realizar o seu ofício. Além disso, evita-se a realização de análises reducionistas sobre o modo de viver dos estudantes.

Dessa forma, pretende-se neste espaço dar visibilidade às reflexões dos jovens acerca do território que habitam cotidianamente. Acredita-se que, escutar suas demandas, realizar provocações a respeito do modo de funcionamento da instituição escolar e do espaço em que vivem sejam maneiras eficazes de contribuir na afirmação da potência destes indivíduos, de forma que tais provocações possibilitem a formação de instrumentos para que se concebam como sujeitos reflexivos, inventivos e autônomos.

\section{METODOLOGIA}

A metodologia escolhida para a pesquisa origina-se de uma forma de intervenção com base no método da cartografia, a partir do qual entende-se a construção do saber-fazer como um acompanhamento de processos, levando-se em consideração a subjetividade enquanto categoria processual e afirmando nosso lugar de não-saber sobre um outro que se reinventa constantemente.

"A cartografia é um método formulado por Gilles Deleuze e Félix Guattari, que visa acompanhar um pro- 
cesso e não representar um objeto. Em linhas gerais trata-se sempre de investigar um processo de produção" (Kastrup, 2009, p. 32). Esta forma de pesquisa rompe com a concepção da ciência moderna baseada em um princípio positivista, que visa separar o sujeito e o objeto de conhecimento por meio de uma suposta neutralidade cientifica.

O "pesquisador cartógrafo" ao habitar um território, encontra processos enrijecidos que constituem o campo a ser pesquisado (Kastrup, 2009). A partir da habitação desse espaço, torna-se possível conhecer como se organizam os campos de forças que cristalizam as relações e o modo de funcionamento do lugar. Desse modo, exige-se que o cartógrafo participe de forma ativa do território, através de uma sensibilidade ao olhar os fatos, afetando-se com os acontecimentos ali vivenciados e ao relacionar-se de forma igualitária com os atores que compõem o ambiente. Entende-se que o processo de pesquisa necessita da construção de uma metodologia inventiva e participativa. A partir da análise das implicações dos processos vivenciados no território propõe-se a criação de novas formas de habitar o campo.

Assim, a construção de uma intervenção em psicologia no ambiente escolar - que objetivou pesquisar os discursos que auxiliam a criminalização da pobreza dos estudantes pertencentes às classes populares - teve a intenção de possibilitar aos indivíduos encontros potencializadores. Estes propiciaram pequenos movimentos capazes de promover rupturas nas relações cristalizadas pela instituição escolar e pelo cenário de desigualdades vivenciadas por jovens em sociedade. Para isso houve a realização de entrevistas individuais e encontros em grupos com os alunos da unidade de ensino, durante o horário escolar.

No primeiro momento, foram realizadas entrevistas individuais com perguntas semiestruturadas, com o objetivo de adquirir informações sobre as vidas dos estudantes e propiciar um espaço de acolhimento. Em seguida, foram realizados onze encontros em grupo a fim de discutir assuntos que atravessam o cotidiano escolar e a vivência dos jovens em sociedade. Os temas apresentados nos encontros foram escolhidos a partir das falas dos participantes, utilizando dispositivos como dinâmicas, textos e reportagens, que se apresentavam como ferramentas atraentes à juventude e propiciavam um campo de reflexão e problematização.

Dessa forma, o trabalho em grupo mostrou-se como um espaço capaz de produção de desindividualização, coletivização das demandas dos indivíduos, escuta, acolhimento e inventividade, no qual se apostou na legitimação de todos os modos de ser e estar no mundo. Além disso, o estudo tomou como base a análise dos diários de campo produzidos durantes os encontros e as falas dos atores que compõem o espaço, por isso entende-se a necessidade em oferecer neste texto uma escrita participativa, no qual os autores integrem todo o processo relatado, descrevendo suas reflexões e percepções acerca do campo investigado.

\section{Participantes}

Ao ser apresentada a proposta da pesquisa à equipe pedagógica e aos professores da unidade de ensino, pediu-se às funcionárias que elaborassem uma lista com estudantes dentro do perfil desejado para a participação no estudo. A relação totalizou 13 alunos, os quais se situavam na faixa etária de 13 a 15 anos de idade; destes, oito jovens são meninos e cinco são meninas, majoritariamente negros e negras, moradores de favela.

Os participantes, em sua maioria, apresentavam em sua trajetória escolar experiência de reprovação, evasão, "problemas" de comportamento e encaminhamentos ao conselho tutelar. Por possuírem esse histórico escolar, alguns alunos eram pertencentes a uma turma de aceleração no estabelecimento educacional: nove participantes estudavam nessa modalidade de ensino. Em consonância, havia discentes matriculados no sexto e sétimo ano do ensino fundamental. Nesse sentido, organizaram-se as atividades em um horário comum entre eles, para que todos pudessem participar.

Por serem oriundos de encaminhamentos dos profissionais da unidade de ensino, os estudantes demonstraram uma resistência inicial ao trabalho. Desse modo, foi necessária a criação de estratégias capazes de possibilitar a explicação do objetivo do estudo. No primeiro contato com os jovens foi realizada uma roda de conversa, com o uso de dispositivos grupais, os quais funcionaram como facilitadores para a explanação de possíveis dúvidas que surgissem em relação ao trabalho. $\mathrm{O}$ momento foi concebido para que se efetivasse um convite à participação na pesquisa, por isso procurou-se manter uma horizontalidade nessa comunicação, com o intuito de que os jovens se sentissem à vontade para fazer qualquer questionamento, sem nenhuma interrupção ou julgamento.

Durante o diálogo foi necessária a explicação do papel da universidade na sociedade - alguns alunos não sabiam o que se fazia nesse espaço; como se dava a forma de acesso, por exemplo - explicar o que se fazia em uma pesquisa; o que era a psicologia; de que forma um psicólogo poderia atuar no contexto escolar; entre outras questões. Em todo o momento foi evidenciado que a participação era espontânea e que eles poderiam deixar de fazê-la a qualquer momento. Todos receberam autorização de seus responsáveis para a colaboração nesse trabalho.

\section{O território habitado}

Para iniciar a reflexão sobre o processo de criminalização da pobreza nas escolas julga-se necessário apresentar elementos do campo investigado, como 
informações da dinâmica de funcionamento do estabelecimento educacional, a história do bairro, as dificuldades vivenciadas por seus moradores, o cenário atual da Educação no município do Rio de Janeiro, entre outras questões encontradas num território denso e cheio de singularidades. O relato descrito a seguir, registrado em um diário de campo de pesquisa do autor, descreve a conversa com uma professora do estabelecimento educacional e revela particularidades acerca do território pesquisado:

Esperei o horário da saída e conversei com a professora a fim de apresentar a pesquisa, conhecer o seu ponto de vista a respeito dos alunos encaminhados para participação no trabalho $e$ saber mais informações sobre o funcionamento da escola. A profissional demonstrou-se estar cansada e esgotada, entretanto foi muito solícita durante a conversa, que foi bem catártica. Ela é funcionária da escola há vinte e sete anos... considera que trabalha com alunos que convivem em um território hostil, que não convivem numa 'cultura de paz'. Os próprios alunos reconhecem que ali não há uma 'cultura de paz' e acabam reproduzindo isso dentro da sala de aula. A todo momento tem que intervir para que os alunos não se coloquem em risco social. O seu objetivo é mostrar aos alunos que não representa uma figura de disciplina, não quer ser rígida, deseja ficar lado a lado deles. Entretanto, eles devem tê-la como uma figura de respeito. Acredita ser muito complicado trabalhar com a sua turma, precisa a todo instante intervir na resolução de conflitos. Atua o tempo todo com a finalidade de 'apagar incêndios'. Procura estimulá-los a resolver suas questões em paz, pois tem uma coisa que vem deles e faz com que sejam hostis uns aos outros. Ficam sempre agitados, não conseguem parar quietos no seu lugar, provocam uns aos outros a todo instante. Nesse espaço, todos os alunos são vítimas e efetores de bullying, se provocam o tempo todo, gostam de "zoar"... para a pesquisa foram escolhidos os estudantes que mais desrespeitaram as regras de convívio social, mas para a profissional o trabalho poderia ser realizado com todos os alunos da turma em que trabalha (Diário de campo da pesquisa, dia 11/04/2017).

A unidade de ensino é uma das 1016 escolas municipais de ensino fundamental que, em 2017, integravam a rede pública municipal de ensino da cidade do Rio de Janeiro, ao lado de 518 unidades de educação infantil (SME-RJ, 2019). Pode ser considerada, em nível estrutural, uma unidade escolar de médio porte, possui 700 alunos distribuídos em 20 turmas de educação infantil e ensino fundamental. O funcionamento ocorre em dois turnos letivos; o primeiro turno, compreende o horário de $07 \mathrm{~h} 30 \mathrm{~min}$ às $12 \mathrm{~h} 30 \mathrm{~min}$ e o segundo turno, de $13 \mathrm{~h}$ às $17 \mathrm{~h} 30 \mathrm{~min}$.

O estabelecimento educacional localiza-se próximo ao Complexo Cidade Alta, no bairro de Cordovil, região pertencente ao subúrbio da Leopoldina, zona norte do Rio de Janeiro. Segundo dados do Índice de Desenvolvimento Humano (IBGE, 2010), entre os 126 bairros do município do Rio de Janeiro, o bairro de Cordovil ocupa a 98 a posição, com IDH de 0,791, apresenta expectativa de vida de 68,32 anos e $\mathrm{R} \$ 290,49$ de renda per capita, ao passo que o bairro da Gávea, localizado na zona sul da cidade, ocupa o 1a lugar na lista, com IDH de 0,970, apresenta expectativa de vida de 80,45 anos e renda per capita de $\mathrm{R} \$ 2139,56$. Os dados explicitam a desigualdade existente na cidade do Rio de Janeiro.

A Cidade Alta surgiu como um conjunto habitacional construído no alto de um pequeno morro, dentro do projeto de erradicação de favelas executados pelo governo federal e estadual nas décadas de 1960 e 1970. O Complexo é formado pelos conjuntos habitacionais Cidade Alta, localizado na região central, Porto Velho - conhecido como "Pé Sujo" - e Vista-Mar- conhecido como "Bancários" -, além de cinco favelas: Divineia, Pica-Pau, Serra Pelada, Chega Mais e Avilã, que foram construídas nas elevações, às margens dos conjuntos. A população local é estimada em 23 mil habitantes, segundo a Prefeitura Municipal do Rio de Janeiro, ou 40 mil, segundo a associação de moradores. A atuação de grupos ligados ao tráfico varejista de drogas e o aumento da violência no local, em oposição ao clima de tranquilidade apresentado até o início dos anos 1980, é o principal fator responsável pelo caráter de favela da Cidade Alta (Brum, 2011).

As favelas, periferias, comunidades em vulnerabilidade social, locais onde pessoas pobres habitam, não recebem do Estado investimentos de forma igualitária como outras regiões das cidades. Faltam investimentos em áreas essenciais, como saúde, educação, habitação, iluminação, entre outros serviços. Esse quadro pode ser observado na fala de um estudante da escola, participante da pesquisa, ao ser questionado sobre o que poderia ser mudado na localidade: "Mudar a Cidade Alta para melhor, porque está ruim. Está faltando prefeito, é culpa dele. Os ônibus estão tendo pouco lá em cima, tem que asfaltar as ruas, os buracos que têm lá em cima" (D., 15 anos).

Além da falta de investimentos em infraestrutura, os moradores convivem com os altos índices de violência na região. Atualmente, o Complexo Cidade Alta é marcado por intensos tiroteios ocasionados pela disputa do controle do comércio varejista de drogas entre grupos rivais, além de constantes operações policiais, que visam reprimir o tráfico na região, a fim de causar uma suposta 
sensação de segurança à sociedade. Frequentemente os estudantes da unidade de ensino têm suas vidas alteradas devido à violência: as aulas são canceladas quando ocorrem tiroteios, o que impede o acesso de centenas de estudantes aos bancos escolares. A situação pode ser verificada através do diálogo registrado entre dois alunos durante um encontro em grupo:

[L., 14 anos:] Como a professora, a diretora, sabendo que vai ficar tendo guerra ${ }^{2}$, como ela vai botar aula? Aí vai, nós estamos aqui na escola e começa o tiroteio de novo? [B., 14 anos:] Mas já aconteceu isso aqui. Na hora da saída aconteceu um tiroteio, bala para lá e para cá e a professora segurou a gente. [L., 14 anos:] Aí tu vai perder a tua vida por causa de escola? [B., 14 anos:] Tá Maluco. Vou nada. Tenho muita coisa para viver ainda.

O medo exposto pelos estudantes põe em visibilidade um modelo de gestão das cidades cujos pobres são mais penalizados (Oliveira, Rezende, \& Bicalho, 2018), o que autoriza a realização de medidas repressivas em regiões populares durante o horário escolar. Por trás desse contexto encontra-se uma estratégia eficaz de criminalização da juventude pobre e negra, a qual fundamenta as políticas públicas, especialmente relacionadas à segurança, que é responsável pela organização de operações policiais.

Segundo dados da Secretaria Municipal de Educação, descritos na matéria "Escolas fechadas pela violência" (2017), nos primeiros 102 dias letivos do ano de 2017, apenas em sete deles a Rede de Ensino da cidade do Rio de Janeiro funcionou com todas as escolas abertas, de um total de 1537 unidades. Nesse período, 382 foram fechadas pelo menos um dia por conta da violência no seu entorno; 129.504 alunos foram afetados pelo fechamento das escolas.

Durante a realização da pesquisa de campo, segundo informações da Secretaria Municipal de Educação obtidas via lei de acesso à informação, a unidade de ensino no qual foi realizado o estudo, no primeiro semestre de

\footnotetext{
${ }^{2} \mathrm{O}$ estudante refere-se à disputa local entre grupos armados rivais pelo controle do comércio varejista de drogas. Há mais de um ano, desde 15 de novembro de 2016, o Comando Vermelho e o Terceiro Comando Puro estão em enfrentamento pelo domínio da região. O Complexo Cidade Alta possui uma localização considerada estratégica na cidade, entre rodovias que ligam o Rio de Janeiro a outros estados da região Sudeste, como a rodovia Washington Luiz (Minas Gerais) e a via Dutra (São Paulo). Além das principais ligações da cidade: a Avenida Brasil, que liga o centro à zona oeste e corta a zona norte, e a Linha Vermelha, principal via de acesso ao Aeroporto Internacional Tom Jobim e à Baixada Fluminense. Frente ao aumento do número de roubo de cargas na cidade em 2017, segundo dado do Instituto de Segurança Pública (ISP), configura-se um dos motivos para essa região ser alvo de constante disputa (G1, 2017; Gonçalves, 2017).
}

2017, teve o seu funcionamento interrompido por três dias letivos por decorrência de operações policiais e confrontos entre grupos armados rivais.

A disputa pelo comércio varejista de drogas local afeta diretamente as relações dos alunos, caracterizando um desafio a ser enfrentado pelos atores pertencentes ao estabelecimento educacional - alunos, professores e equipe pedagógica. $\mathrm{O}$ corpo discente é formado, em grande parte, por moradores do bairro de Cordovil; contudo, possui também estudantes que são moradores de favelas localizadas em bairros vizinhos - que estão sob domínio de grupos armados rivais. A fala a seguir, registrada numa conversa com um estudante, revela como a violência transpõe os muros da escola e interfere na vida escolar:

... nesta escola aqui, os moleques brigam por causa de tudo, de facção. Esses moleques brigam tudo por causa de facção... Tem o C. ele mora em [Parada de] Lucas, eles ficam mexendo com o C., aí eu fico defendendo... Ele é ameaçado por causa que lá e de [Terceiro Comando Puro] terceiro. [Parada de] Lucas é [Terceiro Comando Puro] TCP e o TCP invadiu a Cidade Alta, nesta escola aqui ele é o único de lá e eu tenho uma tia que mora lá. Depois que eu perguntei onde ele mora, a gente começou a ser amigo. [O facilitador da entrevista pergunta:] por que você acha que isso acontece dentro da escola? [O aluno responde:] Necessidade não tem de acontecer, porque uma facção é uma facção. Se for ter problema com uma facção, você resolve com o bandido e não com o morador. [O facilitador da entrevista pergunta:] Eles fazem parte da facção? [O aluno responde:] Não, só se acham que é do [Comando Vermelho] CV. Tipo, tu é TC, eu sou CV, para mim tu é alemão ${ }^{3}$. Aí os moleques falam: olha lá o alemão, alemão, vamos pegar. Aí eles vão te meter a porrada. [0 facilitador da entrevista pergunta:] quem é do $\mathrm{CV}$ e quem é do TCP aqui na escola não podem ser amigos? [O aluno responde:] Isso. (J., 15 anos).

Trabalhar em uma unidade escolar localizada entre favelas dominadas por grupos rivais, sob forte influência de conflitos armados, exige um desafio ainda maior dentro de um contexto de educação. Os atores que compõem o espaço convivem com os efeitos ocasionados pela ausência histórica por parte do poder público na realização de investimentos em áreas essenciais à sobrevivência dos moradores de territórios populares.

Além disso, relacionam-se com os impactos ocasionados pela ineficiência na gestão das políticas públicas, especialmente às políticas de segurança pública, cujo foco localiza-se em uma lógica de guerra às drogas,

${ }^{3}$ Entende-se como pessoa que se identifica ou reside numa favela sob o comando de um grupo rival. 
provocando a presença diária de confrontos e a morte de milhares de jovens negros e pobres, moradores das localidades. Dados do Instituto de Segurança Pública (ISP) revelam que, entre janeiro e setembro de 2017, 813 pessoas foram vítimas de homicídios decorrentes de oposição à intervenção policial no estado do Rio de Janeiro (UOL, 2017). Assim, o Estado escolhe estar presente nestes espaços através de medidas repressivas, contribuindo com a violência e a opressão de seus moradores.

Na sociedade moderna, a instituição escolar é um grande instrumento de socialização, portanto, entre os muros dos estabelecimentos educacionais surgem questões que devem ser analisadas para além desses muros. Para intervir nos conflitos existentes nas escolas torna-se fundamental conhecer elementos do modo de funcionamento de um território tão singular como as favelas, compreender as relações sociais que constituem o território, além de realizar questionamentos acerca do modelo de gestão política e econômica das cidades (Cunha \& Bicalho, 2018).

Sendo assim, ao considerar essas dimensões, pontua-se a necessidade da problematização de práticas e discursos que enunciam noções de ausência, carência e homogeneidade como elementos de percepções reducionistas e de classificações hierárquicas das periferias em relação aos demais espaços da cidade (IMJA, 2018). Dessa forma, os territórios populares não podem ser somente concebidos pela sociedade como lugar de "falta", mas devem ser reconhecidos por sua potência de criação e inventividade, que coabitam os bancos escolares por parte dos seus alunos - moradores das localidades. Assim, o saber oriundo das favelas deve ser valorizado e fazer parte do espaço escolar.

Apresentados alguns elementos constituintes do campo de pesquisa, julga-se necessário lançar o olhar para a história por meio de uma genealogia a fim de compreender como vem sendo desenhado o modelo de educação para as juventudes (Castro \& Bicalho, 2013) de classes populares na sociedade.

\section{O PROCESSO DE CRIMINALIZAÇÃO DA POBREZA E A EDUCAÇÃO}

O processo histórico que fomentou a criminalização da pobreza no Brasil está enraizado na sociedade desde a Idade Média, herança de mais de 300 anos de escravização, além de admiradores na sociedade de teorias racistas e eugênicas, que emergem no século XIX, na Europa, e a iminência do modelo de trabalho capitalista que ampliou a pobreza, desigualdade e violência (Coimbra, 2001).

Segundo Dornelles (1988), os processos de criminalização correspondem à constituição histórica e social de sistemas normativos. O autor considera que as regras de uma sociedade estão fundamentadas em um código penal, que apresenta definições sobre o que é o crime e fundamenta as práticas que podem ser consideradas aceitáveis, além de legitimar as que fogem de uma normalidade. Desse modo, quando as regras são transgredidas, produzem-se punições aos indivíduos. Essas normas serão parâmetros para classificar quais serão os sujeitos considerados ontologicamente perigosos em sociedade. Dessa forma, a criminologia surge como um saber interdisciplinar que objetiva analisar as ligações entre norma, transgressão e punição (Dornelles, 1988).

A partir dessa lógica, estima-se necessário realizar a diferenciação entre dois instrumentos constituintes do modo de subjetivação dos indivíduos em sociedade: os processos de incriminação e criminalização. O primeiro refere-se às leis penais e os castigos correspondentes às transgressões dessas leis. $O$ segundo relaciona-se às transgressões de normas, que não são penais, mas arquitetadas por uma moral, social e cultural (Baratta, 2013). Os processos de criminalização possuem forte interesse para a Psicologia por abranger aspectos subjetivos e ajudam a determinar quais grupos sociais recebem tratamentos diferenciados na sociedade, operando por meio de uma lógica de individualização, culpabilização e estigmatização dos indivíduos.

Desse modo, o processo de criminalização da pobreza impacta negativamente a vida dos sujeitos, produzindo exclusão e estigmatização. Esses derivados de um comportamento de um indivíduo normatizado e normalizado, no qual pobreza, periculosidade e criminalidade estão intimamente ligadas. Por essa ótica, justifica-se a utilização de mecanismos disciplinares contra uma parcela específica da população.

$\mathrm{Na}$ atualidade, os negros, pobres e moradores de áreas periféricas das cidades fazem parte do grupo que recebe um olhar diferenciado do Estado e da sociedade. Para Reishoffer e Bicalho:

Mecanismos de controle social são gestados
e aumentam os argumentos que defendem a
violação dos direitos humanos para os setores
mais vulneráveis da população. Justamente estes
que, por incapacidade de consumo e pela pouca
possibilidade de inserção no mercado, passam a
ser alvo das políticas repressivas de controle social
e de segurança pública. (Reishoffer \& Bicalho,
2009, p. 434).

Os resultados dessas medidas podem ser verificados através das informações publicadas no Atlas da Violência de 2017. O estudo realizado pelo Instituto de Pesquisa Econômica Aplicada (IPEA) e pelo Fórum Brasileiro de Segurança Pública (FBSP) revela que os jovens são os maiores alvos da violência, 318 mil foram assassinados no Brasil entre 2005 e 2015, sendo a população negra, jovem e de baixa escolaridade a maior parte das vítimas de homicídios. Em 2012, o risco de um jovem negro ser 
vítima de homicídio era 2,6 vezes maior do que um jovem branco. A pesquisa evidencia que a experiência de ser negro está intimamente atravessada pela violência, pois de cada 100 pessoas que sofrem homicídio no país, 71 são negras. Estas possuem chances $23,5 \%$ maiores de serem assassinados em relação a brasileiro de outras raças (Cerqueira et al., 2017).

A partir dos dados apresentados pelo estudo, percebe-se a existência de um genocídio da juventude negra e pobre brasileira. Retira-se dessa população a oportunidade de possuir um direito básico a todo ser humano: o de viver. Contudo, quando se tem tal direito assegurado, este ocorre de maneira precarizada. Os jovens convivem com a ineficiência por parte do Estado na implementação de políticas públicas que Ihes possibilitariam as garantias básicas à sobrevivência, como acesso à educação, saúde, moradia e segurança.

Numa sociedade que conjuga tantos mecanismos para a exclusão da população preta, o racismo revela-se como um fator importante nos processos de criminalização, pois baseia-se na ideia de que "algumas raças são inferiores a outras, atribuindo desigualdades sociais, culturais, políticas, psicológicas, à "raça" e, portanto, legitimando as diferenças sociais" (Zamora, 2012, p. 565).

Nesse sentido, a manutenção do racismo configura-se em uma estratégia capaz de unir dispositivos que visam contribuir com o genocídio do povo negro. Esse estrutura-se através de discursos médicos, científicos, educacionais, políticos, da área de segurança, dos meios de comunicação, que objetivam o desaparecimento do negro brasileiro e encontram-se espalhados por todo o meio social. Dessa forma, a morte física que atinge essa população por meio de políticas de extermínio é somente uma face do projeto genocida brasileiro (Nascimento, 2017).

Associado a esse contexto social, a escola pública é reconhecida pelo alto número de evasão escolar e experiências de fracasso por parte de seus alunos. Existem diversas formas de vivenciar esse fracasso; a instituição escolar é conhecida por produzir modos e padrões de comportamento, e culpabiliza os seus estudantes por não conseguirem adequar-se ao espaço.

Desde o seu surgimento no século XIX, com o advento de uma gigantesca série de instituições, que visam enquadrar o indivíduo ao longo da sua existência, a escola atuaria na correção das virtualidades dos indivíduos através de uma "ortopedia social". Trata-se de uma forma de poder classificado como sociedade disciplinar, que vai inaugurar a idade do controle social (Foucault, 2003). A disciplina está instaurada como prática da instituição, a ponto de capturar as singularidades dos indivíduos. Em nome do controle, autoriza-se que se elejam modelos de comportamentos, que devem ser seguidos por todos.
$\mathrm{O}$ aluno que respeitasse as normas estabelecidas pela instituição escolar deveria ser considerado o modelo para os demais. $O$ indivíduo que fugisse desta lógica deveria ser considerado o desviante, que precisaria ser disciplinarizado para habitar o espaço. Por essa ótica, a escola assumiria o papel de transformar os indivíduos em cidadãos, tornando-se responsável por ensinar os 'pré-requisitos básicos' para a convivência em sociedade, além de explicar os conteúdos essenciais para a sua escolarização. Dessa forma, o espaço escolar funcionaria "como uma máquina de ensinar, mas também de vigiar, de hierarquizar, de recompensar" (Foucault, 2011, p. 242).

O questionamento de um estudante acerca do modo de funcionamento de uma unidade escolar expressa como a instituição consegue exercer o controle dos corpos e das subjetividades dos indivíduos: "Isto aqui parece uma cadeia, a gente não pode fazer nada. Tu já viu quanto pessoal que tem aqui pra tomar conta de criança? Você não pode correr, fazer nada" (D. 15 anos). A instituição escolar, ainda hoje, funciona como um aparelho biopolítico e disciplinar do Estado, capaz de regulamentar as vidas dos indivíduos. Assim, alunos, professores e funcionários das escolas são capturados por esse modelo, e fazem funcionar o espaço por meio de uma lógica disciplinar.

Além disso, os estudantes das escolas públicas, oriundos das classes mais empobrecidas da sociedade, em sua grande parte, negros e moradores do subúrbio das grandes cidades são vítimas de "discursos institucionais que tendem a produzir repetições, mesmice, na tentativa de prescrever o igual e garantir a sua permanência" (Kupfer, 1997, p. 54). Atravessada pela cristalização desses discursos ao cumprir o seu papel de escolarização, a instituição escolar silencia os seus alunos ao apresentar dificuldade em capturar a singularidade dos indivíduos.

Os alunos que não se enquadram neste modelo, tornam-se vítimas de um perigoso processo de estigmatização e exclusão, são rotulados como 'bagunceiros' e 'maus alunos' por habitar a escola de maneira 'diferenciada'. O barulho, a conversa fora de hora, as agitações presentes em salas de aulas são rechaçadas como algo fora do 'normal'. Discursos individualizantes e preconceituosos são eliciados na instituição, produzindo modos de ser e estar na sociedade, elegendo modelos de família e priorizando grupos sociais específicos.

A pobreza é percebida como fruto do fracasso pessoal, de incapacidades individuais, de preguiça, de falta de determinação (Patto, 2015). Os problemas encontrados na escola tendem a ser analisados fora de contexto, de maneira reducionista e afetam a vida dos indivíduos. Para justificar a experiência de fracasso encontrada em sala de aula, os estudantes pobres são responsabilizados pelo seu baixo rendimento, procuram-se explicações 
no modo de criação de suas famílias a fim de justificar o 'mau comportamento', os problemas relacionados à evasão escolar e repetência. A questão do "fracasso da escola" ${ }^{4}$ (Paixão, 2003) não costuma ser analisada para além destas questões: o sistema de ensino vigente, as práticas presentes em salas de aula e os problemas ocasionados pela falta de investimentos por parte do poder público na área de educação, não são colocados em análise. $O$ infortúnio está localizado no indivíduo, na sua família, no seu bairro, no seu modo de viver em sociedade. Portanto, ao reproduzir discursos preconceituosos e excludentes, a instituição escolar contribui ativamente com o crescente movimento de criminalização da pobreza na sociedade.

\section{O QUE PODE A PSICOLOGIA NAS ESCOLAS?}

Frente ao cenário de criminalização das camadas populares na sociedade, torna-se necessário analisar o papel da psicologia nos estabelecimentos educacionais. Por meio de uma práxis política envolvida numa leitura crítica do contexto social nos quais inserem-se os sujeitos, a atuação do psicólogo deve estar comprometida, principalmente, com a afirmação de potência dos indivíduos, com a redução de práticas reducionistas e excludentes nas unidades escolares.

Segundo Patto (2015), a partir de uma análise histórica da formação da Psicologia no Brasil, verifica-se que o campo psi estruturou-se no país, entre os anos de 1930 e 1970, sobgrande influência do saber médico. "Os primeiros trabalhos brasileiros de interesse psicológico foram teses de conclusão de curso nas faculdades de medicina da Bahia e do Rio de Janeiro, ainda no século passado" (Patto, 2015, p. 76). Na faculdade de medicina da Bahia, a Escola Nina Rodrigues foi responsável pela realização de estudos relacionados a higiene mental, a criminologia e a psiquiatria forense, ao passo que no Rio de Janeiro foram realizados trabalhos sobre os desvios relacionados à mente humana.

Nesse período circulavam com força teorias de cunho racistas advindas da Europa, que legitimavam diferenças raciais e asseguravam uma superioridade da cultura europeia e da raça branca. Esses discursos foram os principais responsáveis pela organização do pensamento racial no país.

Nesse sentido, o médico Arthur Ramos - um dos principais admiradores e propagadores da obra de

\footnotetext{
${ }^{4}$ Faz-se o uso do termo utilizado pela autora Lea Paixão (2003). Para ela: "A literatura pedagógica costuma englobar evasão, abandono, repetência sob a expressão 'fracasso escolar', que prefiro substituir por 'fracasso da escola'... "fracasso generalizado de todas as esferas em ação no espaço escolar" (Paixão, 2003, p. 55). Neste sentido, "fracasso da escola" retira o caráter individual que o termo "fracasso escolar" carrega, com o objetivo de realizar uma leitura institucional e política acercadas questões apresentadas pelos indivíduos no espaço escolar.
}

Nina Rodrigues - pode ser considerado uma grande referência na formação de uma psicologia educacional no país. Ele foi um dos responsáveis pela criação e desenvolvimento de clínicas e centros de higiene mental escolar, localizados em escolas públicas da cidade do Rio de Janeiro. Nestes espaços buscava-se estudar e corrigir os desajustamentos infantis diagnosticados em crianças que apresentavam distúrbios de aprendizagem, por meio da realização de procedimentos oriundos da psicologia inferencial, como testes psicológicos, os quais tinham como objetivo diagnosticar os desvios psíquicos. Instaurou-se o termo 'crianças-problema' para referir-se aos indivíduos que passavam por tratamentos e precisavam ser ajustados (Patto, 2015).

Além disso, por meio da produção de trabalhos científicos, a medicina exerceu grande influência na formação de profissionais da educação no país, ao analisar os problemas de aprendizagem escolar. Identificavam-se como causas desses desvios aspectos físicos, emocionais, de personalidade e intelectuais. Em seus escritos, Ramos difundiu o conceito de carência cultural para justificar o dito traço primitivo do povo brasileiro; para o autor os negros trazidos para o Brasil eram atrasados em nível cultural e acabaram contaminando toda a população (Patto, 2015).

Dessa forma, a psicologia era responsável por identificar a "carência" das crianças-problema, à medida que, em sua maioria, eram oriundas de ambientes considerados primitivose/ou populares. Assim, este campo no espaço escolar contribuiu para uma prática voltada a enquadrar os indivíduos a uma norma, atravessada por teorias racistas, que desconsiderava os atravessamentos históricos e sociais que constituem os sujeitos.

\section{COM A PALAVRA, OS ESTUDANTES: O QUE PODE A PSICOLOGIA NAS ESCOLAS?}

Ao iniciar a pesquisa-intervenção na unidade de ensino, os participantes foram questionados sobre o que a psicologia poderia fazer no espaço. As respostas, em sua maioria, foram atravessadas pela lógica de uma prática psicológica marcada pelo o ajustamento dos indivíduos:

Pode ajudar muitas pessoas aqui dentro
da escola, cada maluco que tem nesta
escola (L., 14 anos). Procurar saber mais sobre as pessoas, conversar, isso é que eu acho, aconselhar... Não é o meu caso, mas tem gente que vem com um problema de casa e não tem ninguém para conversar, para desabafar, a psicologia é boa para fazer isso (T., 14 anos).

Para esses alunos, a psicologia possui técnicas e mecanismos capazes de enquadrá-los numa norma aceita pela sociedade. Estigmatizados pela sua condição de alunos-problema na escola e atravessados pela 
criminalização de sua existência, recorrem à psicologia para auxiliar no desejo de sair desse modo, que os inferiorizam enquanto sujeitos. A fala a seguir evidencia esse desejo:

Não sou muito perfeita porque tenho o meu jeito favelado, mas muita gente gosta de mim... na escola eu não faço mais, a diretora fala que é feio e eu respeito ela, mas na rua eu faço assim [mexe com as mãos], levanto o pé, grito. Mas não muito. [O facilitador pergunta:] Esses comportamentos, esses gestos, só acontecem na favela, as pessoas em outros lugares não levantam a mão ao falar, por exemplo? [A aluna fica em silêncio e o facilitador da entrevista pergunta:] Por que você acha que esse é um jeito favelado? Não acho que é um jeito favelado, mas no jeito que eu sou, todo mundo fala. Eu não gosto que os outros me chamam de favelada, sou nascida e criada na comunidade da Cidade Alta, mas eu não gosto que os outros me chamam de favelada (H., 13 anos).

Em uma instituição que utiliza dispositivos disciplinares para normatizar os comportamentos dos indivíduos, o "jeito favelado", não é aceito. O modo de comportamento da aluna é rechaçado no estabelecimento educacional por atores que compõem o espaço e pela própria estudante. Atravessados por um modo de produção de subjetividade, "essencialmente fabricada - como parte do processo de produção do sistema capitalístico - a qual interfere na maneira como os indivíduos percebem o mundo, se articulam com ele, com a ordem social, sustentando as forças produtivas" (Will, 2015, p. 23).

Os modos de ser e estar no mundo que se afastam da lógica eurocêntrica, cujas práticas escolares foram influenciadas, são culpabilizados e vistos como algo fora da 'curva de normalidade' - comportamentos considerados inadequados no estabelecimento escolar, por exemplo. Logo, os indivíduos que seguem essa lógica devem ser enquadrados para comportar-se de maneira adequada e se adaptar a fim de tornar-se um 'bom aluno' no estabelecimento educacional que, para a estudante acima citada e o imaginário escolar, não engloba o "jeito favelado".

Dessa maneira, contribui-se para a manutenção de práticas e discursos carregados de preconceitos por parte de atores dos estabelecimentos educacionais e pela individualização das questões apresentadas pelos sujeitos no espaço. Por sua vez a psicologia, ao ser convocada na escola, pode ser responsável por atenuar o processo de criminalização dos alunos, na atuação em conflitos escolares, auxiliando na diminuição da propagação da lógica de judicialização da vida presente na sociedade (Cunha \& Bicalho, 2018). O fragmento a seguir revela essa perspectiva do trabalho: $O$ pessoal da sala falou que você é do Conselho Tutelar e vai levar a gente (L., 14 anos).

O conselho tutelar é um equipamento criado com o advento do Estatuto da Criança e do Adolescente, com o objetivo de garantir os direitos das crianças e dos adolescentes. "A característica singular do conselho tutelar é não ser do âmbito da justiça, mas a sua existência está diretamente vinculada a uma lei, o que tem contribuído para que use métodos da justiça" (Scheinvar, 2012, p. 48). A fala do aluno, carregada por medo e desconfiança, revela como este dispositivo vem sendo apresentado nas escolas como um mecanismo de punição e controle. Ao deparar-se com uma pessoa diferente no espaço, que lhe faz questionamentos sobre a sua vivência, o estudante o assimila como alguém deste espaço, que visa enquadrar o seu comportamento. Ao ser chamada na instituição escolar, a psicologia pode assumir essa função através de um especialismo, capaz de reduzir as demandas escolares em aspectos individuais e psicologizantes, operando por meio do uso de dispositivos capazes de produzir medo e ameaça aos indivíduos.

Desse modo, a psicologia, ao habitar o chão de uma escola pública atravessada por infinitas particularidades, precisa fazer uma leitura crítica do espaço, conhecer as singularidades que compõem a instituição escolar e contribuir para que não haja a manutenção de práticas excludentes. A práxis psicológica não pode estar a serviço para o uso de mecanismos das leis, como punição e culpabilização dos atores da instituição escolar. Neste sentido, a psicologia deve assumir o protagonismo na luta pela construção de políticas públicas que ofereçam a criação de uma escola pública de qualidade e que não contribuam com a lógica de judicialização da vida existente em sociedade.

\section{CONSIDERAÇÕES}

Na emergência de oferecer conclusões ao texto, é necessário compreender que ao analisar os discursos produzidos nas escolas que auxiliam a criminalização da pobreza, não se pretende determinar 'culpados' ou 'inocentes' pela manutenção de práticas excludentes nos estabelecimentos educacionais. Atualmente, o modelo escolar oferecido a estes alunos é oriundo de um sistema político, econômico e social, que criminaliza e culpabiliza os pobres por sua condição de existência na sociedade.

Desse modo, a todo instante são executadas medidas institucionais nos espaços por eles ocupados, como as favelas, as escolas públicas, visto os dados divulgados pelo Atlas da Violência 2017 e o quantitativo de escolas públicas fechadas no Rio de Janeiro devido às operações policias durante o horário escolar, anunciados neste trabalho.

Miguel Arroyo (2015) traz indagações pertinentes a serem feitas sobre o contexto educacional no sistema capitalista, na sua fase neoliberal, em que vivemos: 
Uma pergunta se impõe a nossa ética profissional, escolar e pedagógica: como essas imagens morais tão negativas da adolescência e da juventude pobre e negra, nem moralizável nem educável, mas exterminável, terminam afetando o imaginário social e escolar sobre os educandos/as populares que vão chegando às escolas públicas? Como terminam negando seu direito à educação? (Arroyo, 2015, p. 33).

Atravessados por esse contexto social, os atores que compõem as escolas, ao realizarem as suas funções, por muitas vezes reproduzem discursos que legitimam a exclusão e criminalização das classes populares. Além disso, sentem-se culpados por não conseguirem cumprir as suas atividades, numa sociedade regulada por competitividade e produtividade. O trecho de um diário de campo dos autores relata uma conversa com uma professora da unidade de ensino que evidencia esse sentimento:

Aproximando ao fim do ano letivo, numa manhã chuvosa de segunda-feira, vou à escola para conversar com a professora. Gostaria de saber como estavam os alunos que participaram da pesquisa. Combinei com a profissional de encontrá-la depois do horário da saída. Quando toca o sino - avisando para os estudantes que havia chegado o horário de ir para casa - vou ao seu encontro em frente à sala de aula, em que trabalha. Ela pediu que esperasse, pois havia alunos que ainda não tinham terminado de fazer a atividade. Espero, sentado em uma das cadeiras, observando o seu modo de relacionarse com os alunos da turma. Toda a preocupação demonstrada pela profissional com os jovens deixou-me encantado. Pacientemente, mesmo que seu horário já tivesse sido cumprido, ia de mesa em mesa ajudá-los. Em seguida, gentilmente recebeume para conversarmos. Pergunto-Ihe como estavam os estudantes. Em sua resposta, falou-me das dificuldades vivenciadas nesse ano letivo, por conta dos intensos conflitos existentes na região: queixou-se do fato de seus alunos chegarem agitados e só quererem falar sobre as situações tristes vivenciadas na favela durante as aulas, como os tiroteios e as questões relacionadas ao conflito entre os grupos armados - fato que a deixa muito incomodada. Reclamou por diversas vezes de como a violência afeta o rendimento dos alunos à medida que, em muitos dias, as aulas foram canceladas e os estudantes ficavam com medo de ir à escola, por causa do clima de insegurança. Esses fatos dificultam a seguir o planejamento acadêmico, para cumprir os prazos criados pela prefeitura teve que correr muito para ensinar todos os conteúdos. Em sua fala contou detalhes sobre a vida dos jovens, toda vez que um aluno deixava de frequentar as aulas, fazia questão de ligar para os responsáveis a fim de saber o motivo pela ausência. Quando não conseguia efetuar contato com os familiares, perguntava aos outros estudantes. Nove alunos de sua turma participaram do estudo, segundo ela, apenas três estudantes continuaram em sua classe. Diversos acontecimentos ocorreram durante o ano letivo: dois alunos foram transferidos para outras escolas da região por não se comportarem de maneira adequada; dois estudantes foram morar com outros familiares em outros bairros da cidade por estarem se colocando em situações de "risco social" na favela; uma aluna parou de frequentar as aulas e não procurou outra unidade escolar para concluir o ano letivo; um aluno, segundo os outros estudantes moradores da região, fugiu de casa e está "andando com arma na favela". Estes fatos fazem com que a profissional fique muito desanimada a realizar o seu ofício, sente-se esgotada, por considerar que não consegue atingir os estudantes. Afirma que não gostaria de vê-los como mais "um aluno a entrar no tráfico". Para ela: "o seu código de validade está vencido" $e$ precisa começar a pensar em sua aposentadoria... (Diário de campo, 23/10/17).

A individualização e a culpabilização são dois dispositivos eficazes utilizados pelo Estado no capitalismo. Problemas de ordem estrutural tendem a ser analisados de forma individual. Nesse sentido, os indivíduos introjetam para si a responsabilidade dos infortúnios vivenciados. Esta é uma estratégia eficaz utilizada por gestores que administram a máquina pública a fim de não encontrar soluções eficientes para os problemas vivenciados em sociedade. Pensar em transformações estruturais no sistema escolar em um momento de retrocessos no campo de direitos sociais em que viemos, configura-se em um grande desafio.

Desta forma, para habitar o chão das escolas públicas neste contexto, os atores deste espaço - professores, coordenadores pedagógicos, funcionários dos estabelecimentos educacionais - precisam apostar numa micropolítica capaz de suscitar pequenos acontecimentos, que produzam transformações cotidianas na instituição escolar e se comprometa com a afirmação de potência dos estudantes. Sendo assim, torna-se necessário lutar pela construção de um novo modelo de escola, que aposte na desindividualização das questões dos indivíduos e reconheça os seus estudantes oriundos das camadas populares como - verdadeiramente sujeitos de direito. Repensar o funcionamento é uma forma política de evitar a contribuir na manutenção de práticas e discursos, que auxiliam num modelo de 
escola excludente, cujos estudantes pobres não cabem.

À psicologia cabe o papel de potencializaras pequenas ações diárias que são realizadas nos estabelecimentos educacionais, como o caso de uma profissional que busca a integração entre a família e escola, por exemplo. Operar pela via da diferença, acreditar no coletivo e nas potencialidades dos indivíduos são formas potentes deste campo contribuir na construção de um espaço escolar que seja para todas e todos.

\section{REFERÊNCIAS}

Arroyo, M. G. (2015). O direito à educação e a nova segregação social e racial - Tempos insatisfatórios? Educação em Revista, 31 (3), 15-47.

Baratta, A. (2013). Criminologia Crítica e Crítica do Direito Penal: Introdução à Sociologia do Direito Penal. Rio de Janeiro: Revan.

Bicalho, P. P. G. (2013). Ditadura e Democracia: qual o papel da violência de Estado? In Conselho Regional de Psicologia do Rio Grande do Sul (Ed.), Entre Garantia de Direitos e Práticas Libertárias (pp. 13-34). Porto Alegre: Conselho Regional de Psicologia do Rio Grande do Sul.

Bortolini, A.; Bicalho, P. P. G.; Mostafa, M.; Colbert, M.; Polato, R.; Pinheiro, T. F. (2014). Trabalhando Diversidade Sexuale de Gênero na Escola: currículo e prática pedagógica. Rio de Janeiro: Pró-Reitoria de Extensão da Universidade Federal do Rio de Janeiro.

Brum, M. S. (2011). Cidade Alta: História, memórias e estigma de favela num conjunto habitacional do Rio de Janeiro. Tese de Doutorado, Universidade Federal Fluminense, Niterói-RJ.

Cassal, L. B. C.; Gonzalez, A. G. M.; Bicalho, P. P. G. (2011). Psicologia e o dispositivo da sexualidade: biopolítica, identidades e processos de criminalização. Psico, 42, 465 - 473.

Castro, A. C.; Bicalho, P. P. G. (2013) Juventude, território, Psicologia e política: intervenções e práticas possíveis. Psicologia: Ciência e Profissão, 33 (n. spe), 112-124.

Cerqueira, D.; Lima, R. S.; Bruno, S.; Valencia, L. I.; Hanashiro, O.; Machado, P. H. G.; Lima, A.S. (2017). Atlas da Violência 2017. Recuperado em 28 agosto, 2017, de http://www.ipea. gov.br/portal/images/170609_atlas_da_violencia_2017.pdf

Coimbra, C. M. B. (2001). Operação Rio: o mito das classes perigosas. Rio de Janeiro: Oficina do Autor/Intertexto.

Cunha, T. C.; Bicalho, P. P. G. (2018). Por uma concepção política de conflito escolar. Revista de Psicologia, 9 (1), 70-80.

Decotelli, K. C. M.; Cunha, T. C.; Bicalho, P. P. G. (2016). Criminalização da vida escolar: entre policiais, (in)segurança e conflitos emergem os processos de medicalização e judicialização. In Lemos, F. C. S.; Galindo, D.; Bicalho, P. P. G.; Ferreira, E. T. A.; Cruz, B. A.; Nogueira, T. S.; Neta, F. T. B.; Aquime, R. H. S. (Eds.), Práticas de Judicialização e Medicalização dos Corpos, no contemporâneo (pp. 194212). Curitiba: CRV.

Dornelles, J. R. W. (1988). O que é crime. São Paulo: Brasiliense.
Escolas fechadas pela violência. Recuperado em 25 de novembro de $2017 \mathrm{http}: / /$ prefeitura.rio/web/sme/ exibeconteudo?id=7157726,

Foucault, M. (2003). A verdade e as Formas jurídicas. Rio de Janeiro: Nau.

Foucault, M. (2011). Vigiar e Punir. Petrópolis: Vozes.

Gonçalves, J. (2017, 02 de maio). Rio de Janeiro toma conhecimento da guerra na Cidade Alta após cinco meses de confronto. The Intercept. Recuperado em 08 de novembro de 2017, de https://theintercept. com/2017/05/02/rio-de-janeiro-toma-conhecimento-deguerra-na-cidade-alta-apos-cinco-meses-de-confronto

G1 (2017, 23 de junho). Roubo de cargas no Rio aumenta mesmo com a presença da Força Nacional. Recuperado em 24 de novembro de 2017, de https://g1.globo.com/ rio-de-janeiro/noticia/roubo-de-cargas-no-rio-aumentamesmo-com-a-presenca-da-forca-nacional.ghtml

IMJA (2018). Carta da Maré, Rio de Janeiro - Manifesto das periferias: As periferias e seu lugar na cidade. Revista Periferias, 1 (1).

Instituto Brasileiro de Geografia e Estatística [IBGE] (2010). Tabela 1172 - Índice de Desenvolvimento Humano Municipal (IDH), por ordem de IDH, segundo os bairros ou grupo de bairros. Recuperado de www.data.rio/datasets/ 72b9b673a6e64e398d974a8fa7c6628a

Kastrup, V. (2009). O funcionamento da atenção no trabalho do cartógrafo. In Passos, E.; Kastrup, V.; Escóssia, L. (Eds.), Pistas do método de cartografia: pesquisa-intervenção e produção de subjetividade (pp. 32-51). Porto Alegre: Sulina.

Kupfer, M. C. M. (1997). O que toca a/à Psicologia Escolar. In Machado, A. M.; Souza, M. P. R. (Eds.), Psicologia escolar: Em busca de novos rumos (pp. 55-65). São Paulo: Casa do Psicólogo.

Melsert, A. L. M.; Bicalho, P. P. G. (2012). Desencontros entre uma prática crítica em psicologia e concepções tradicionais em educação. Psicologia Escolar e Educacional, 16 (1), 153-160.

Nascimento, A. D. (2017). O genocídio do negro brasileiro: processo de um racismo mascarado. São Paulo: Perspectiva.

Oliveira, M. F.; Rezende, R. A. S. S.; Bicalho, P. P. G. (2018). Direitos Humanos, Segurança Pública e a produção do medo na contemporaneidade. Cadernos Brasileiros de Saúde Mental, 10 (25), 118-140.

Patto, M. H. S. (2015). A produção do fracasso escolar: histórias de submissão e rebeldia (4a ed.). São Paulo: Intermeios.

Paixão, L. P. (2003) A escola dos carentes: um projeto em Minas Gerais. In Arroyo, M. G. (Ed.). Da escola carente à escola possível (pp. 55-84). São Paulo: Loyola.

Reishoffer, J. C.; Bicalho, P. P. G. (2009). Insegurança e produção de subjetividade no Brasil Contemporâneo. Fractal: Revista de Psicologia, 21, (2), 425-444.

Scheinvar, E. (2012). Conselho tutelar e escola: a potência da lógica penal no fazer cotidiano. Psicologia \& Sociedade, 24 (n. spe.), 45-51. 
SME-RJ. (2019). Educação em números. Recuperado em 16 de novembro de 2019, de http://www.rio.rj.gov.br/web/sme/ educacao-em-numeros.

UOL. (2017, 2 dezembro). Em 9 meses, mortes por policiais em serviço passam de 800 no RJ. Recuperado em 02 de dezembro de 2017, de https://noticias.uol.com.br/ cotidiano/ultimas-noticias/2017/11/01/para-cada-policialassassinado-em-servico-no-rj-30-pessoas-sao-mortas-em- acoes-policiais.htm.

Will, V. S. (2015). Vigiar, Punir, Educar e Matar: discursos de disciplinamento, controle e extermínio da população preta e pobre do Rio de Janeiro. Tese de Doutorado, Universidade Federal Fluminense, Niterói, Rio de Janeiro.

Zamora, M. H. R. N. (2012). Desigualdade racial, racismo e seus efeitos. Fractal: Revista de Psicologia, 24(3), 563-578.

Recebido: 26 de maio de 2018 Aprovado: 27 de novembro de 2019 